\title{
SISTEM INFORMASI PENDATAAN TENDER PADA DINAS BINA MARGA PROVINSI LAMPUNG
}

\author{
Fatimah Fahurian, S.Kom ${ }^{1}$, Khozainuz Zuhri, M.Eng² \\ ZA. Pagaralam No. 7, Gedong Meneng, Rajabasa, Kota Bandar Lampung, Lampung 40115 \\ e-mail : ${ }^{1}$ fatimah_fahurian@umitra.ac.id, ${ }^{2}$ zuhri@umitra.ac.id
}

\begin{abstract}
ABSTRAK
Proses pendataan peserta tender pada Dinas Bina Marga Provinsi Lampung masih menggunakan pencatatan dalam buku besar sehingga proses pencarian data masih memerlukan waktu yang relatif lama. Hal inilah yang menjadi dasar untuk mengembangkan sistem informasi pendataan tender. Sistem informasi pendataan tender dibangun dengan tujuan mengetahui masalah - masalah yang dihadapi dalam pendataan tender. Berdasarkan hal tersebut, penelitian ini mengusulkan sebuah sistam yang dapat menghasilkan suatu sistem informasi yang dapat membantu dalam mendata para peserta tender yang ada di Dinas Bina Marga Provinsi Lampun Oleh sebab itu diperlukan sebuah sistem informasi pendataan tender yang mana sistem tersebut diharapkan dapat mengatasi masalah yang terjadi pada proses pendataan peserta tender.
\end{abstract}

Kata kunci : tender, pendataan, sistem informasi

\section{PENDAHULUAN}

\subsection{Latar Belakang Masalah}

Dinas Bina Marga Provinsi Lampung adalah instansi yang bertanggung jawab atas pengembangan dan pemeliharaan seluruh ruas jalan dan jembatan yang ada, baik jalan Kabupaten, Provinsi maupun Jalan Negara. Dalam pengembangan pekerjaan, Dinas Bina Marga memilih sebuah azas untuk melaksanakan kegiatannya. Salah satu azas yang di gunakan yaitu azas desentralisasi, dimana didalam azas ini Dinas Bina Marga Provinsi Lampung bertanggung jawab atas pendanaan, pelaksanaan, pengembangan serta pemeliharaan jalan-jalan dan jembatan Provinsi yang dapat menunjang dalam pertumbuhan sosial ekonomi dan industri pertumbuhan ruas - ruas jalan. Untuk mendukung pekerjaan tersebut maka Bina Marga mengadakan pengadaan barang dan jasa bagi para peserta yang ingin mengikuti tender.

Pada saat ini Dinas Bina Marga dalam mendata peserta tender masih menggunakan pencatatan dalam buku besar sehingga proses pencarian data masih memerlukan waktu yang relatif lama. Oleh sebab itu diperlukan sebuah sistem informasi pendataan tender yang diharapkan dapat mengatasai permasalahan yang ada dalam pendataan tender.

\subsection{Identifikasi Masalah}

Berdasarkan latar belakang masalah tersebut maka dapat diidentifikasi permasalahan yaitu dalam pendataan peserta tender masih menggunakan pencatatan dalam buku besar sehingga proses pencarian data masih memerlukan waktu yang relatif lama.

\subsection{Tujuan Penelitian}

Tujuan dari penelitian ini adalah :

a. Mengetahui masalah - masalah yang dihadapi dalam pendataan tender.

b. Membangun dan menghasilkan suatu sistem informasi yang dapat membantu dalam mendata para peserta tender yang ada di Dinas Bina Marga Provinsi Lampung.

\subsection{Metode Penelitian}

Ada beberapa teknik yang dipergunakan dalam memperoleh data-data tersebut, antara lain: 
1. Teknik obsevarsi

Pada tahap ini peneliti langsung melakukan pengamatan langsung di Dinas Bina Marga Provinsi Lampung.

2. Teknik wawancara (Interview)

Pada teknik ini diadakan dialog langsung dengan ketua panitia tender (pengadan barang dan jasa), dengan tema Sistem Informasi Pendataan Tender pada Dinas Bina Marga Provinsi Lampung .

\section{Tinjauan pustaka (Researce Library)} Tinjauan pustaka di lakukan dengan cara membaca, mengutip, dan membuat catatan yang bersumber pada bahanbahan pustaka yang mendukung dan berkaitan dengan penelitian. Dalam hal ini peneliti mendapatkan data-data dari proses pendataan tender.

\section{LANDASAN TEORI}

\subsection{Pengertian Sistem}

Menurut Jogiyanto HM (2008:34) Terdapat dua kelompok pendekatan dalam mendefenisikan sistem, yaitu yang menekankan pada prosedurnya dan yang menekankan pada komponennya. Pendekatan sistem yang lebih menekan pada prosedur mendefenisikan sistem adalah sebagai kumpulan dari prosedur-prosedur yang mempunyai tujuan tertentu.

Pendekatan sistem yang lebih menekankan pada elemen atau komponennya mendefenisikan system adalah kumpulan dari komponen yang saling berhubungan satu dengan yang lainnya membentuk satu kesatuan untuk mencapai tujuan tertentu.

\subsection{Pengertian Sistem Informasi}

Menurut Tata Sutabri, S.Kom., MM (2003:42) Sistem Informasi adalah suatu sistem di dalam suatu organisasi yang mempertemukan kebutuhan pengolahan transaksi harian yang mendukung fungsi operasi organisasi yang bersifat manajeral dengan kegiatan strategi dari suatu organisasi untuk dapat meyediakan kepada pihak luar tertentu dengan laporan - laporan yang diperlukan.

\subsection{Pengertian Pendataan}

Menurut Tata sutabri (2005:21) data merupakan bahan mentah untuk di olah, yang hasilnya kemudian menjadi informasi. Dengan kata lain, data yang di peroleh harus di ukur dan di nilai baik buruknya, berguna atau tidak dalam hubungannya dengan tujuan yang akan di capai.

\subsection{Pengertian Tender}

Tender adalah upaya temporer untuk menghasilkan produk, jasa atau hasil yang tertentu atau unik. Tender bersifat temporer artinya waktu berlangsungnya dibatasi, ada awal dan ada akhir untuk pekerjaan yang dilakukan dan tim yang dibentuk. Meski begitu, produk atau jasa yang dihasilkan tidaklah bersifat temporer. Unik berarti hasil dari proyek merupakan suatu entitas baru yang memiliki karakteristik yang berbeda dengan hasil yang sudah ada.

(Rudy Tantra, 2012:8)

\subsection{Pengertian Web}

Web adalah salah satu aplikasi yang berisikan dokumen - dokumen multi media (teks, gambar, suara, animasi, vidio) didalamnya yang menggunakan protokol HTTP (hypertext transfer protocol) dan untuk mengaksesnya menggunakan perangkat lunak yang disebut browser.

(M. Rudyanto Arief, 2011:7)

\subsection{Pengertian My SQL}

MySQL adalah salah satu jenis database server yang sangat terkenal dan banyak digunakan untuk membangun aplikasi web yang menggunakan database sebagai sumber dan pegolahan datanya.

(M.Rudyanto Arief, 2011:151) 


\subsection{Pengertian Database}

Database adalah sekumpulan data yang terdiri atas satu atau lebih tabel yang saling berhubungan. (Madcoms, 2007:2)

Database adalah memori long-term dari aplikasi web database. Aplikasi tidak akan dapat memenuhi tujuan tanpa database. (Janner Simarmata, 2006:22)

Dari beberapa pendapat diatas dapat disimpulkan bahwa database sekumpulan data yang saling berhubungan.

\subsection{Bagan Alir Sistem}

Bagan alir sistem (systems flowchart) merupakan bagan yang menunjukan arus pekerjaan secara keseluruhan dari sistem. Bagan ini menjelaskan urut - urutan dari prosedur - prosedur yang ada di dalam sistem. Bagan alir sistem menunjukan apa yang dikerjakan di sistem.. (Jogiyanto, 2005:796)

\section{HASIL DAN PEMBAHASAN}

\subsection{Analisa Sistem yang sedang berjalan} Sistem yang sedang berjalan dalam pendataan tender pada Dinas Bina Marga sebagai berikut

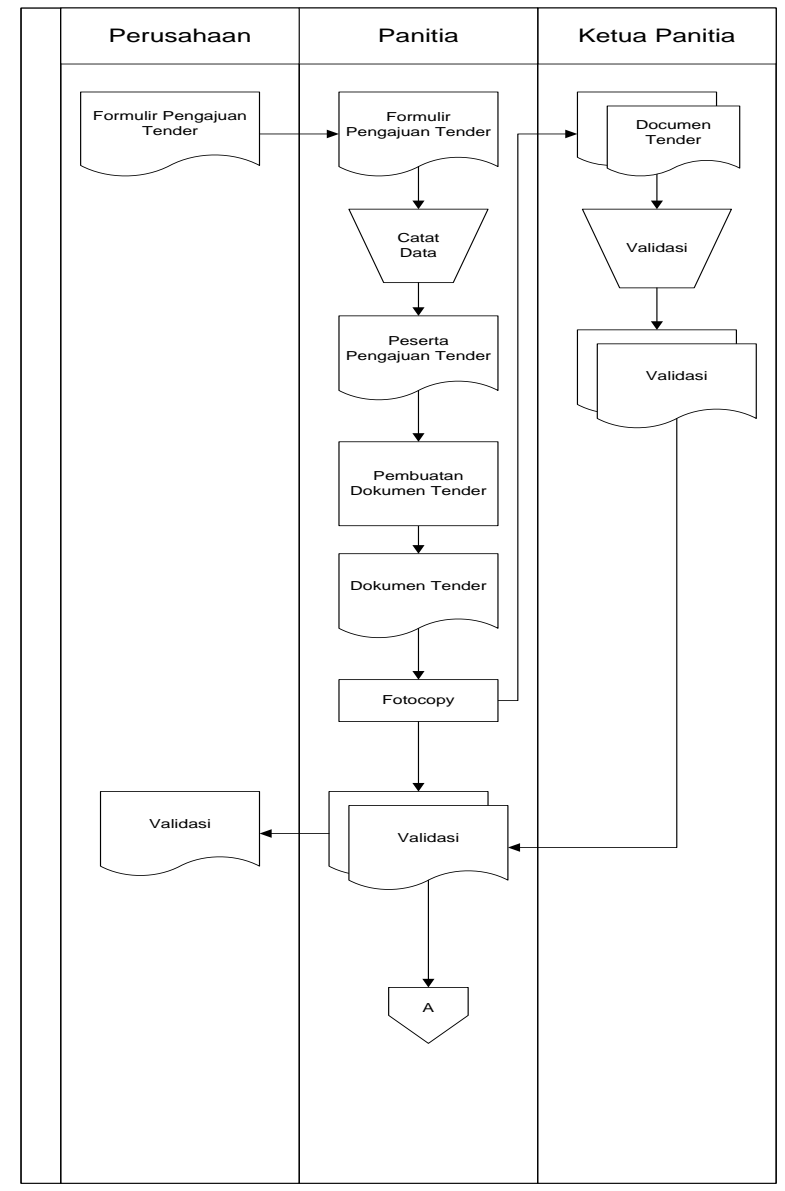

\section{Gambar 3.1 DAD Sistem yang Berjalan}

\subsection{Diagram Konteks Sistem Usulan}

Diagram konteks adalah gambaran umum yang menjelaskan kegiatan keseluruhan proses sistem secara garis besar berdasarkan prosedur kerja yang ada dalam sistem. Diagram konteks menjelaskan hubungan antara Admin dan Perusahaan. Berikut adalah gambar dari diagram konteks sistem yang diusulkan. 


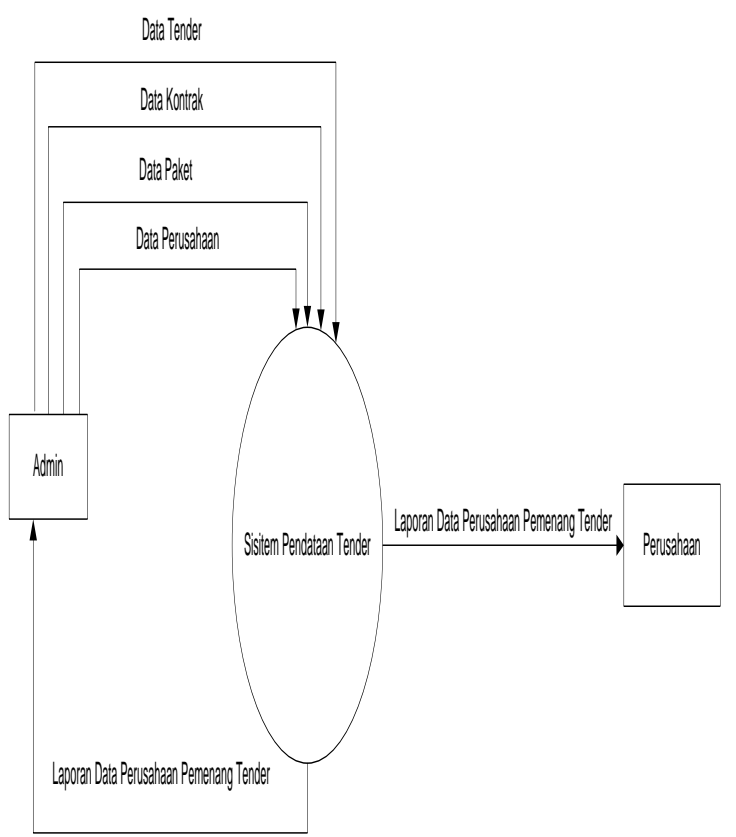

Gambar 3.2 Diagram Konteks

Dari Gambar diatas dapat dipahami bahwa dalam sistem informasi pendataan tender pada Dinas Bina Marga Provinsi Lampung sebagai berikut :

1. Admin menginput data perusahaan,data paket,data kontrak, data tender

2. Kemudian admin menginfomasikan laporan data perusahaan pemenang tender ke perusahaan

3. Setelah itu perusahaan melihat laporan data perusahaan pemenang tender tersebut.

\subsubsection{Diagram Arus Data (Data Flow Diagram) level 0}

Diagram alir data level 0 menggambarkan secara keseluruhan dari diagram konteks yang setiap bagian memiliki hubungan yang terkait dari satu bagian ke bagian yang lain. Setiap bagian tersebut saling berhubungan dan bekerja sama menyelesaikan pekerjaan sesuai dengan tujuan.

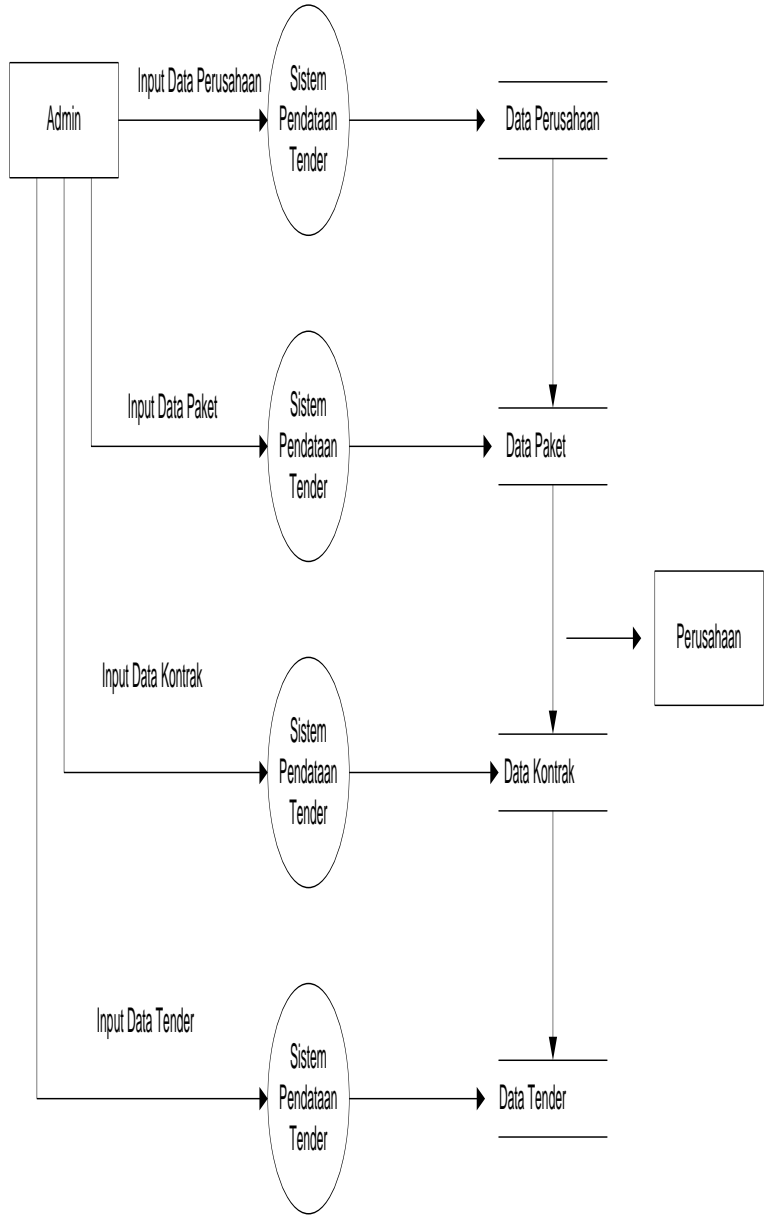

Gambar 3.3 DFD Level 0

\subsubsection{Data Flow Diagram Level 1}

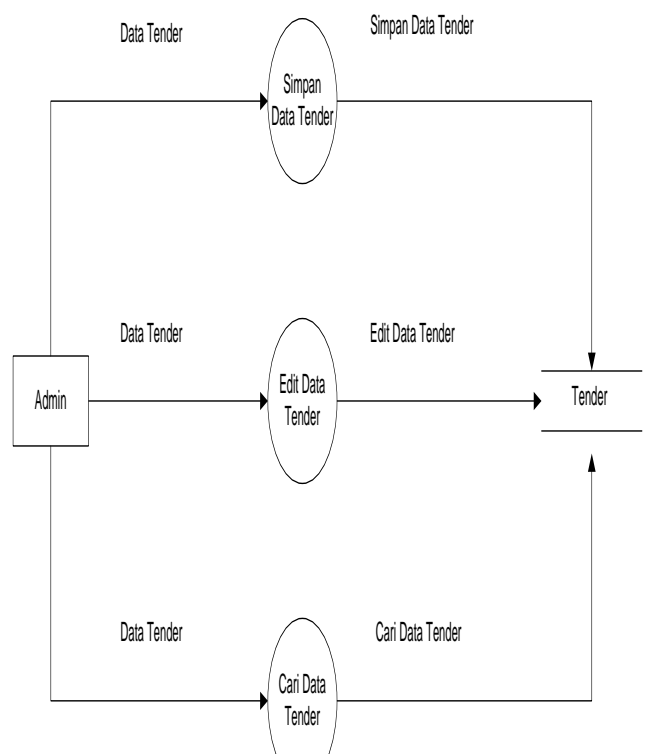

Gambar 3.4 DFD Level 1 


\subsection{Desain Input}

\subsubsection{Input Data Perusahaan}

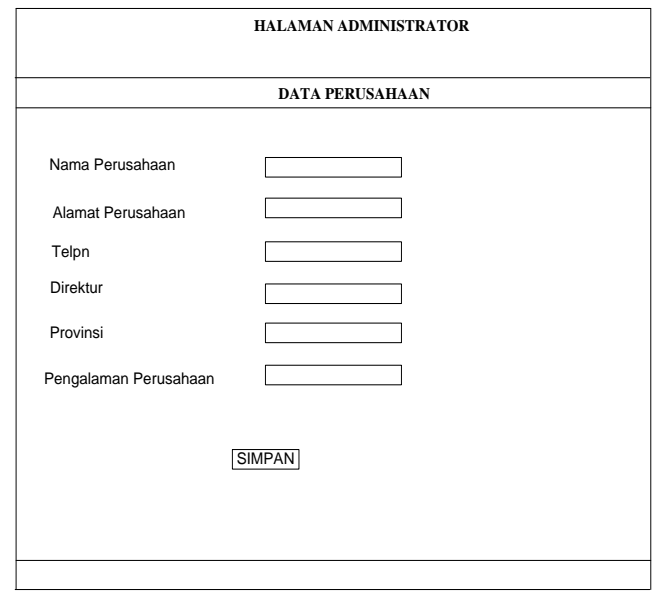

Gambar 3.5 Input Data Perusahaan

\subsubsection{Input Data Paket Tahunan}

\begin{tabular}{|c|}
\hline HALAMAN ADVINISTRATOR \\
\hline DATA PAKET \\
\hline Kode Paket \\
Nama Paket \\
\hline \\
\hline \\
\\
\\
\end{tabular}

\subsubsection{Input Data Kontrak Tahunan}

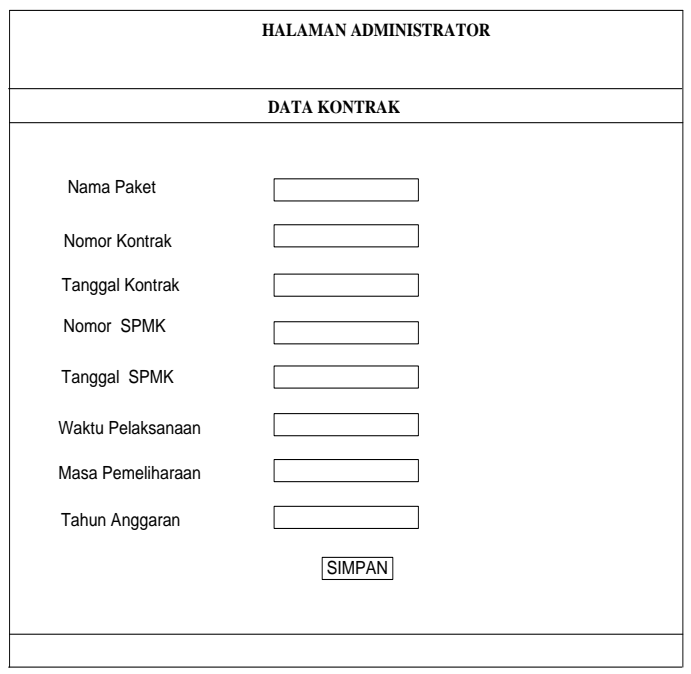

Gambar 3.7 Input Data Kontrak Tahunan

\subsubsection{Input Data Tender}

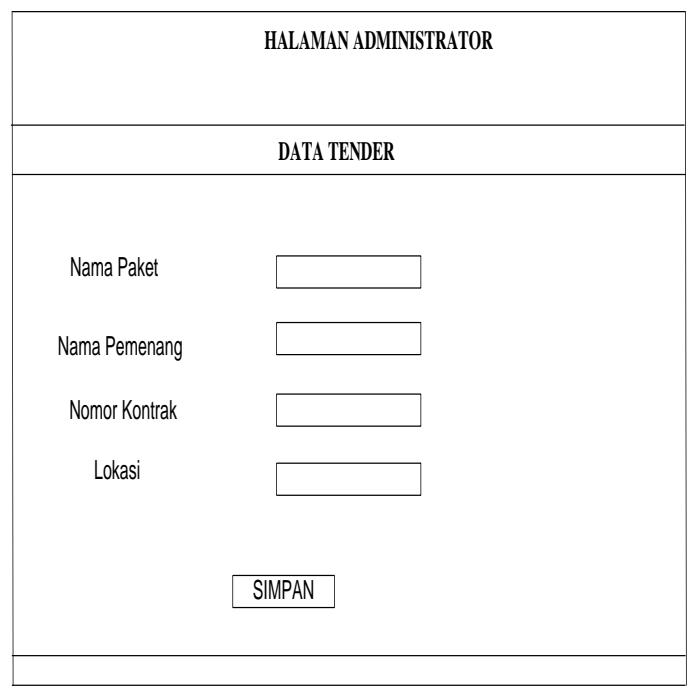

Gambar 3.8 Input Data Tender

Gambar 3.6 Input Data Paket Tahunan 


\subsection{Desain Proses}

Berikut adalah proses Pendataan Tender di Dinas Bina Marga Provinsi Lampung

1. Panitia melengkapi data dokumen tender sebelum melakukan penginputan dan penerbitan pemenang tender dalam sistem.

2. Kemudian admin menginput data perusahaan, paket tahunan, kontrak tahunan, pada sistem pendataan tender.

3. Setelah penginputan dilakukan, maka sistem akan langsung menyimpan data dan menerbitkannya dalam web pengunjung agar di tampilkan dalam website.

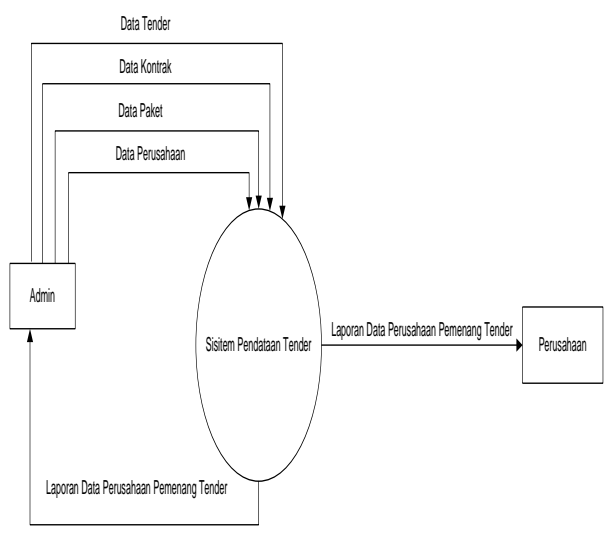

\section{Gambar 3.9 Desain Proses}

\subsection{Desain Output}

Dari hasil data masukan yang telah di proses maka dapat menghasilkan keluaran (output) dari sistem informasi pendataan tender tersebut .

\begin{tabular}{|c|c|c|c|c|c|c|c|c|c|c|}
\hline \multicolumn{11}{|c|}{ Data Pemenang Tender } \\
\hline No & 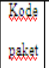 & 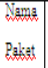 & 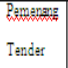 & $\begin{array}{l}\text { Pengeglegen } \\
\text { Perushasen }\end{array}$ & distemet & Tedp & Disieltur & 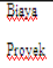 & 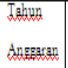 & Golbati \\
\hline 1 & $\mathrm{xx}$ & $\mathrm{xx}$ & $\mathrm{xx}$ & $\mathrm{xx}$ & $\mathrm{xx}$ & $\mathrm{xx}$ & $\mathrm{xx}$ & $\mathrm{xx}$ & $\mathrm{xx}$ & $\mathrm{xx}$ \\
\hline 2 & $\mathrm{xx}$ & $\mathrm{xx}$ & $\mathrm{xx}$ & $\mathrm{xx}$ & $\mathrm{xx}$ & $\mathrm{xx}$ & $\mathrm{xx}$ & $\mathrm{xx}$ & $\mathrm{xx}$ & $\mathrm{xx}$ \\
\hline 3 & $\mathrm{xx}$ & $\mathrm{xx}$ & $\mathrm{xx}$ & $\mathrm{xx}$ & $\mathrm{xx}$ & $\mathrm{xx}$ & $\mathrm{xx}$ & $\mathrm{xx}$ & $\mathrm{xx}$ & $\mathrm{xx}$ \\
\hline 4 & $\mathrm{xx}$ & $\mathrm{xx}$ & $\mathrm{xx}$ & $\mathrm{xx}$ & $\mathrm{xx}$ & $\mathrm{xx}$ & $\mathrm{xx}$ & $\mathrm{xx}$ & $\mathrm{xx}$ & $\mathrm{xx}$ \\
\hline
\end{tabular}

Gambar 3.10 Desain Output

\subsection{Relasi Antar Tabel}

Dari sistem yang di bangun, peneliti mengajukan tabel penyimpanan data yang terelasi sebagai berikut.

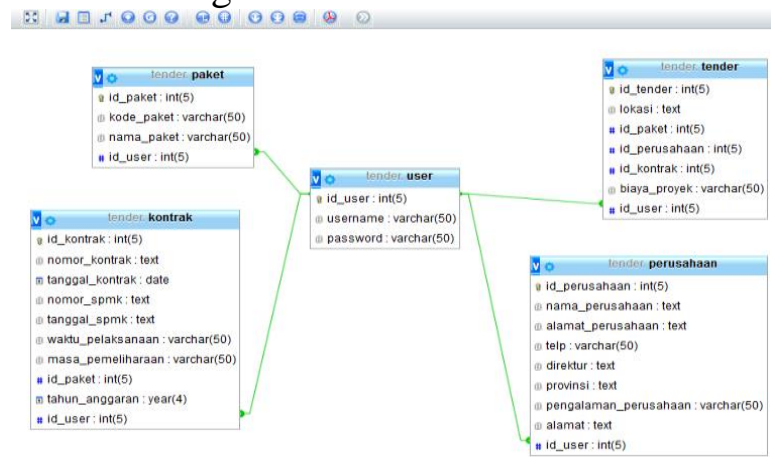

Gambar 3.11 Relasi Antar Tabel

\subsection{Implementasi Sistem}

a. Tampilan Menu Login

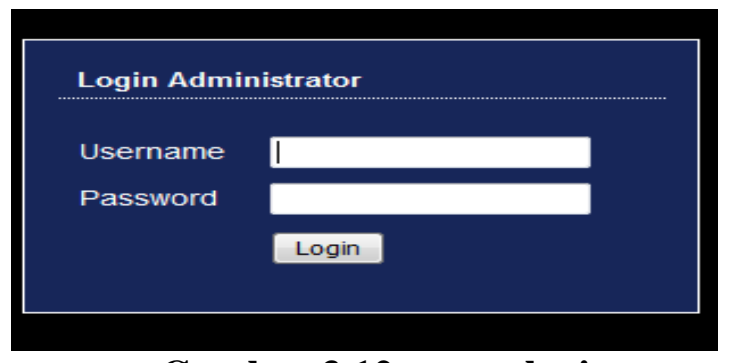

Gambar 3.12 menu login

b. Tampilan Halaman Admin

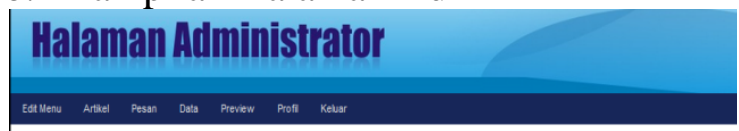

debby ari winardi

Gambar 3.13 Halaman Administrator 
c. Tampilan Halaman Pengunjung

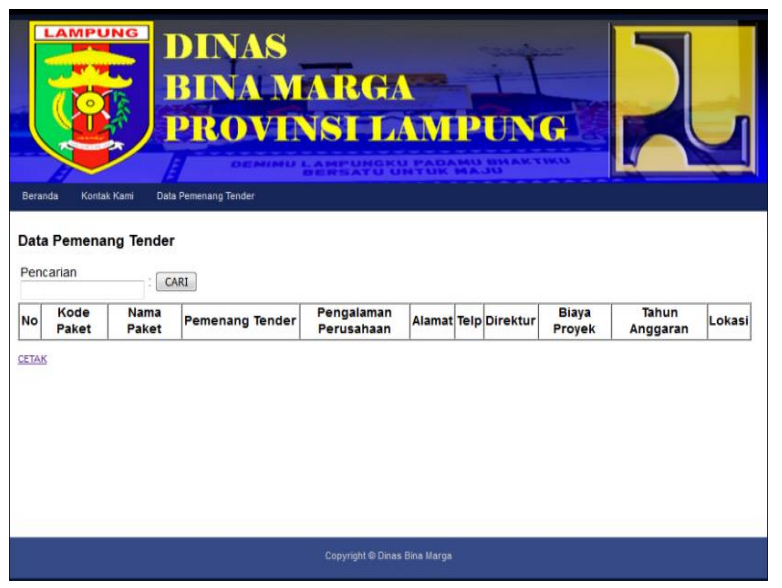

Gambar 3.14 Halaman Pengunjung

\section{PENUTUP}

\subsection{Kesimpulan}

Berdasarkan hasil penelitian di dinas bina marga provinsi Lampung, maka dapat ditarik kesimpulan bahwa :

1. Dalam pendataan peserta tender masih menggunakan pencatatan dalam buku besar sehingga proses pencarian data masih memerlukan waktu yang relatif lama. Sehingga dengan adanya sistem informasi pendataan tender ini diharapkan informasi dapat tersampaikan dengan cepat.

2. Sistem informasi pendataan ini diharapkan dapat memudahkan bagian panitia pengadaan barang dalam mendata tender pengadaan barang di Dinas Bina Marga Provinsi Lampung.

\subsection{Saran}

Berdasarkan kesimpulan diatas maka disarankan kepada Dinas Bina Marga provinsi Lampung adalah sebagai berikut :

1. Sistem informasi pendataan tender pada dinas bina marga provinsi Lampung sebaiknya dikembangkan dengan menambahkan fitur - fitur yang diperlukan oleh dinas bina marga provinsi lampung.
2. Diharapkan sistem yang diusulkan dapat dipergunakan dalam meningkatkan kinerja dalam mendata tender yang ada pada dinas bina marga provinsi lampung sehingga dapat memudahkan dalam proses pencarian data.

\section{DAFTAR PUSTAKA}

[1] Jogiyanto HM. 2005. Analisis \& Desain, Ed ke-III. Andi Offset : Yogyakarta.

[2] Komputer, Wahana. 2010. Panduan Belajar MySQL database server. Media Kita: Jakarta.

[3] Madcoms. 2007. Mahir Dalam 7 Hari Macromedia Dreamweaver 8 dengan PHP. Andi:Yogyakarta.

[4] Peranginangin, Kasiman. 2006. Aplikasi Web dengan PHP dan MySQL. Andi: Yogyakarta.

[5] Rudyanto, Arief, M. 2011. Pemrograman Web Dinamis menggunakan PHP dan MySQL. Andi: Yogyakarta.

[6] Sakur, B, Stendy. 2005. Aplikasi Web Database dengan Dreamweaver MX 2004. Andi:Yogyakarta

[7] Sutabri, Tata. 2005. Sistem Informasi Manajemen. Andi: Yogyakarta.

[8] Sutanta, Edhy. 2011. Basis Data dalam (Tinjauan Konseptual). Andi: Yogyakarta.

[9] Tantra, Rudy. 2012. Manajemen Proyek Sistem Informasi (Bagaimana Mengelola Proyek SI Secara Efektif dan Efisien). Andi: Yogyakarta. 
